found to exhibit only a moderate degree of pelvic contraction, the diagonal conjugate measuring four and a half inches, while the interspinous and intercristal diameters measured nine and a half inches and ten and a half inches respectively.

I am indebted for permission to publish this case to $\mathrm{Mr}$. F. W. S. Mann, as it occurred while I was temporarily taking charge of his practice at Revesby, Lincolnshire.

Birmingham.

\section{THE SURGICAL TREATMENT OF VARICOSE VEINS.}

BY JOHN O'CONOR, M.A., M.D.T.C.D.

SENIOR MEDICAL OFFICER, BRITISH HOSPITAL, BUENOS AYRES.

IN the New York Medical Journal of May 1st, 1897, a paper of mine was published in which $I$ advocated total extirpation of the diseased portion of vein or veins, with primary ligation of the internal saphenous vein at the saphenous opening. As no mention was made of this operation in Treves's System of Surgery, the American Textbook of Surgical Science (Keen and White), or other books at my disposal, I concluded that my procedure was original. During the past six months I have read some sorrespondence in the London medical papers in which Mr. W. H. Bennett and Mr, F. A. Southam expressed satisfaction with the results obtained from similar treatment. Since January, 1896, I have operated on 40 cases and in only JBe instance experienced any serious pcst-operative complication-cedema of the left leg and thigh. This was in a very bad case of varix in which I had to remove the greater part of the external and internal"saphenæ. However, by persistent massage the cedema gradually subsided and the patient is now (tbree years after) quite cured.

Having been disappointed with relapses following the old method of removing a number of pieces I came to the conclusion that a complete excision was necessary to establish a permanent cure. I think that if any surgeon were to thoronghly expose the affected area in a severe case of varices he would readily perceive that multiple incisions and ligations must frequently prove futile owing to what one might almost call the labyrinthal distribution of the contorted veins and their tributaries. At times $I$ have found it most difficult to avoid button-holing or scoring the skin when the diseased veius were densely adherent to it; the only way to prevent this is by keeping the edge of the knife constantly turned towards the vein, even at the risk of cutting into it, which, after all, is a small matter which can be easily remedied by a pressure forceps. Whenever I committed the above error I invariably paid the penalty of having necrosis of the skin follow, which, needless to say, kept the patient in bed for months instead of weeks. It is in this class particularly that operation is most necessary, for sooner or later the adhering congeries of veins seriously interferes with the blood-supply of the skin, and ulceration or rupture, or both, supervene

The operation which I have practised during the past four years is as follows. The limb having been shaved and disinfected from Poupart's ligament to the ankle a two-inch incision is made over the saphenous opening and the internal saphenous vein is doubly ligated and divided; if no varicosity is present above the knee the wound is closed and dressed at once with dry sterilised gauze. If the femoral portion is affected the vein is dissected up after ligation at the saphenous opening and its branches are seized with pressure forceps and ligated. Generally, if varices are present above the knee there are also some below, and when such is the case the incision is prolonged downward directly over the vessel until the lowest limit of the disease is reached. In the last case on which I operated I had to make an incision 27 inches long, through which I removed 43 inches of diseased internai saphenous vein and branches. If the varices do not extend above the knee, after occluding the saphenous trunk as described above, an incision is made over the affected portion, a ligature is applied above and below, and the whole intervening mass is removed by dissection. All branches are caught up with pressure forceps and when the main channel is removed they are ligated with fine catgut. As frequently the external saphenous vein is also affected its varicose portion is dealt with in a similar matter. To some this plan way appear formidable, yet if the internal saphenous is primarily ligated at the saphenous opening there is little danger of emboli, \&c. I have also employed this method for removing thrombosed veins occurring during and after pregnancy with most satisfactory results, and in six cases' of phlebitis I found extirpation concluded the matter. In closing these long wounds I consider the blanket suture recommended by Cheyne and Burghard most useful, as it can be rapidly inserted and does not strangle the tissues like the old continuous suture.

Buenos Ayres, Argentina.

\section{BLOOD DUST OR BLOOD GRANULES: A NEW CONSTITUENT OF THE BLOOD?}

\section{BY EDWARD G. HORDER, F.R.C.S. EDIN.}

For some years the small dancing bodies in the plasma of the blood have proved a veritable mare's nest to many workers. What are they? and where do they come from? have been questions often asked, but with no satisfactory forthcoming reply. Last year I made some attempts to solve the problem and answer the questions. While experimenting in various ways to obtain this happy resuit I employed eosin, pricking through a drop placed on the finger-tip, at once transferring the blood to cover and slide, and examining under a one-twelfth immersian lens and No. 4 eye-piece. The small dancing bodies, so often mistaken for -dirt, malarial parasites, \&c., could be easily seen in the blood plasma, bat my attention was reserved entirely for the leucocytes. The granules in the white cells began to move most vigorously, and after watching them for some minutes it was noticed that they (the granules) were extruded from the cell, scattered all over the field, and juined those already in the plasma. It was easily observed that the daucing: bodies seen in the plasma before the extrusion of the granules were identical with those which but a moment before had been a constituent of neutrophile or eosinophile leucocyte. After the excrusion of the granules a pinkstained nucleus only was to be seen. My colleague, Mr. Hill and Mr Deane of the Imperial Maritime Customs bindly examined a specimen aud concurred with me in the conclusions I had formed.

The above was forwarded to Professor Halliburton and Dr. Manson last year, but owing to the rage for foreign stamps was, with many other letters, not delivered. My observations in consequence were not published. A few weeks ayo I received the third edition of Cabot's book on the blood and saw that Müller and Stokes had discovered a "new constituent of the blood" and christened it "blood dust" From the account given it appears that we have been working on the same lines and I reyset not having seen any communications giving a description of their observations. In my opinion "blood dust" is no new constituent of the blood, being nothing more than the extrusion of the granules from the leucocytes, but if these dancing bodies in the plasma must be named why not place them under the title of blood granules, seeing that this is the term applied to them before their extrusion from the leucocytes?

Pakhoi, South China.

University College, Cardiff.-At the Engineers' Institute, Cardiff, on Oct. 6th, Professor A. W. Hughes of King's College, London, delivered the annual address to students, taking as his subject "The Present Condition of Medical Education." Mr. J. L. Treharne presided. Professor Hughes, who was the first professor attached to the medical department of Cardiff College, in the course of an interesting lecture, which will be found at p. 1000, referred to the Cardiff Medical School and said that the time had now come to complete it so that it might become a great medical centre. He added that they would need an endowment for the patbological department and said he wished that some publicminded citizen would make such a provision. A subsequent speaker stated that about $£ 25,000$ would be required to establish a complete medical school for Cardiff. 